\title{
The Effect of an Integrated Health System Specialty Pharmacy on HIV Antiretroviral Therapy Adherence, Viral Suppression, and CD4 Count in an Outpatient Infectious Disease Clinic
}

\author{
Elizabeth Barnes, PharmD, BCACP, AAHIVP; Jing Zhao, MD, PhD; \\ Adam Giumenta, CPhT; and Marc Johnson, MD
}

\begin{abstract}
BACKGROUND: Adherence to antiretroviral (ARV) therapy is critical in order to achieve and maintain viral suppression and improve immune function. Clinical pharmacists and pharmacies focused on human immunodeficiency virus (HIV) have demonstrated the ability to increase ARV medication adherence and subsequently have a positive effect on these lab markers.
\end{abstract}

OBJECTIVES: To evaluate the effect of an integrated health system specialty pharmacy service with a clinic-embedded, HIV-trained pharmacist and pharmacy technician on ARV medication adherence rate, viral load, and CD4 count.

METHODS: This was a single-center, retrospective cohort study conducted from August 7, 2017, to June 30, 2018, at an indigent outpatient infectious disease clinic within Atrium Health ( $\mathrm{AH})$, a not-for-profit health system based in Charlotte, NC. The intervention group (opt-in group) received HIV patient care that involved the health system specialty pharmacy service. Once a patient was enrolled in the specialty pharmacy service, medication reconciliation was completed by the pharmacist, financial assistance and prior authorizations were completed if needed; prescriptions were delivered to the patient; and monthly refills calls were conducted to assess adherence, tolerability, and medication changes. The control group (optout group) received HIV patient care that did not incorporate the health system specialty pharmacy. The primary endpoints were medication adherence, viral suppression, and CD4 counts. Within-group comparisons from baseline to follow-up were made along with group-to-group comparisons. Adherence was calculated using medication possession ratio.

RESULTS: For those patients using Atrium Health Specialty Pharmacy Service (AH SPS; $n=46$ ), the overall median adherence rate was higher at $100 \%$ versus only $94 \%$ for those patients $(n=50)$ that opted out of the service $(P<0.01)$. All but 3 patients $(21.7 \%$ at baseline vs. $6.5 \%$ at followup, $P=0.03$ ) using AH SPS reached viral suppression, and all but 1 had improved immune function with a CD4 count of 200 or greater by the end of the observation period $(P=0.03)$. The change in viral suppression and CD4 count of 200 or greater was not statistically improved between baseline and follow-up in those opting out of using AH SPS. When comparing the 2 groups at reaching these endpoints, there was no statistically significant difference in viral suppression and CD4 count.

CONCLUSIONS: AH SPS was able to demonstrate improved ARV adherence in those patients using an integrated specialty pharmacy with an embedded pharmacy team, coordinated monthly medication delivery, and refill reminder and adherence calls. This in turn led to improved viral suppression and immune markers by the end of the observation window for patients using AH SPS.

J Manag Care Spec Pharm. 2020;26(2):95-102

Copyright $\odot 2020$, Academy of Managed Care Pharmacy. All rights reserved.

\section{What is already known about this subject}

Human immunodeficiency virus (HIV) continues to be a serious health issue in the United States, with an estimated 1,122,900 adults and adolescents living with HIV at the end of 2015, of which approximately $46 \%$ are living within the southern United States.

Optimal adherence to HIV therapy is critical to achieve and maintain viral suppression, which in turn improves immune function and reduces the risk of transmission and new infections. HIV-focused pharmacies and clinical pharmacists, as experts in medication management, have been shown to play a key role in helping to promote and assist with medication adherence.

\section{What this study adds}

This study demonstrated that an integrated health system specialty pharmacy within an outpatient infectious disease clinic increases adherence to antiretroviral therapy, as well as improves viral suppression rates and CD4 counts among those patients using its services.

Because the management of HIV-infected patients is a highly specialized area of practice, these patients may especially benefit from the high-touch care that is provided by this type of integrated practice model.

$\mathrm{H}$ uman immunodeficiency virus (HIV) continues to be a serious health issue, with more than 36 million people worldwide infected. Within the United States, more than 1.1 million adults and adolescents were living with HIV at the end of 2015, including an estimated 15\% who were undiagnosed. In 2015, of all HIV-infected adults, only $48 \%$ were retained in continuous HIV care, and 49\% were virally suppressed. While HIV infection is still a national issue, the epicenter of the epidemic has now shifted to the South. The southern states have experienced the greatest burden of HIV infection of any U.S. region, with an estimated $46 \%$ of all HIV infected patients residing in the South. This region also accounts for more than half of all new HIV diagnoses., ${ }^{1,2}$

A key component in helping to alleviate the burden of HIV in the South is to ensure that patients are adherent to 
treatment regimens. Nearly all patients who adhere to antiretroviral (ARV) therapy are able to achieve and maintain viral suppression, which is critical to restoring immune function, improving survival, preventing the development of resistance, and reducing transmission..$^{3-5}$ Previous research has reported that adherence at a rate of $95 \%$ or greater is necessary for optimal ARV efficacy. While in other disease states, lower adherence rates of $80 \%$ are considered reasonable, adherence of less than $95 \%$ in patients with HIV can be correlated to increased resistance, as well as to poorer outcomes.$^{6-8}$ For example, in a study at a free HIV clinic, it was found that when adherence levels were below 95\%, the percentage of patients with viral loads consistently below 400 copies per $\mathrm{mL}$ (copies $/ \mathrm{mL}$ ) fell below $60 \% .{ }^{9}$

Pharmacists have specialized knowledge of medication use and can play a key role in helping to promote and assist with adherence in HIV-infected patients. Several studies have shown that community pharmacies with specially trained and educated HIV pharmacists had higher ARV refill adherence. More specifically, Hirsch et al. (2009) found that patients using HIV medication therapy management programs in place at $10 \mathrm{com}-$ munity pharmacies in California were more likely to be classified as adherent with a medication possession ratio (MPR) of 80\%-120\% over those using nonspecialized community pharmacies $(56.8 \%$ vs. $38.1 \%, P<0.001) .{ }^{10}$ A study by Cocohoba et al. (2012) compared 4,254 patients using HIV-focused community pharmacies with 11,679 patients using traditional pharmacies and found that patients using an HIV-focused pharmacy had significantly higher regimen refill adherence as measured by median MPR (90\% vs. $77 \%, P<0.0001){ }^{11}$

To correlate pharmacist-directed adherence counseling with improved clinical outcomes, a 2018 study from an infectious disease (ID) clinic in New Mexico demonstrated that embedded clinic pharmacists conducting adherence counseling for ARV not only increased adherence but also improved CD4 counts and decreased viral loads. ${ }^{12}$ Specifically, this study demonstrated that mean CD4 count improved from 298 to 454 at 6 months, and median viral load decreased from 48,000 copies $/ \mathrm{mL}$ to all participants being undetectable ( $<20$ copies $/ \mathrm{mL}$ ) at 6 months. ${ }^{12}$ Another study that was conducted by Kaiser Permanente Northern California demonstrated that in clinics with embedded clinical pharmacists, patients tended to be more likely to achieve a viral load $<500$ copies $/ \mathrm{mL}$ at 12 months. ${ }^{13}$

While there is plenty of evidence to suggest that specialized community/dispensing pharmacies and clinic-embedded pharmacist involvement in HIV care promote positive outcomes, there is a lack of data evaluating the effect of integrating a health system specialty pharmacy, which combines the dispensing and clinical components, into an ID clinic. An integrated health system specialty pharmacy is unique because it has the ability to connect the patient, provider, pharmacist, and pharmacy at the point of care. Also, all involved members of the care team have access to the electronic medical record (EMR), which provides all relevant patient data such as laboratory test values, progress notes, and clinic appointments. EMR messaging allows the specialty pharmacy to easily communicate with the rest of the team if there are concerns about compliance, financial hardship, or adverse drug events. ${ }^{14}$

To our knowledge, there is only 1 other study that has specifically evaluated and described this concept. ${ }^{15}$ Northwestern Medicine specialty pharmacy created an HIV service line in 2014 that connected its specialty pharmacy to existing clinical pharmacists embedded within an ID clinic. This integration has allowed for closed-loop medication management in HIVinfected patients by providing medication education, prescription fulfillment, assistance with medication access, medication delivery, refill reminder calls, identification of barriers to adherence, side effect management, reduction of drug-drug interactions, and treatment monitoring. ${ }^{15}$

Atrium Health (AH), a health system based in Charlotte, NC, currently cares for over 5,000 HIV-infected patients across 6 different counties through 3 urban outpatient ID clinics. Of these patients, approximately 3,000 have a gross family income that is equal to or less than $300 \%$ of the federal poverty guidelines. In August 2017, AH Specialty Pharmacy Service (SPS) integrated care by embedding a 2-person team that consisted of an HIV clinical pharmacist and pharmacy technician within 1 of the 3 health system outpatient ID clinics. The Myers Park ID clinic was selected as the first location to integrate the SPS model, since it is a safety net clinic serving underinsured patients, many of whom are impoverished and have low literacy, along with adherence issues and concomitant mental health and substance abuse disorders. Our study aimed to assess the effect that an integrated health system specialty pharmacy has made on clinical outcomes for HIV-infected patients with insurance billable by AH SPS.

\section{Methods}

\section{Study Design}

This was a single-center, retrospective cohort study conducted in the Myers Park ID Clinic from August 7, 2017, to June 30, 2018. The evaluation received quality improvement exemption from the AH Institutional Review Board. The Myers Park ID Clinic currently cares for HIV-infected patients through 5 fullday clinics per week from 3 different HIV-trained physicians. Before August 2017, there was no specialty pharmacy integration. The intervention group included all HIV-infected patients with contracted insurance plans who agreed to enroll in $\mathrm{AH}$ SPS between August 7, 2017, and December 31, 2017. The control group consisted of patients with contracted insurance plans who opted out of using AH SPS during this same period and continued to manage their own refills through nonintegrated, external pharmacies. Their response to opt in or opt 
out of using our health system specialty pharmacy was tracked in an encrypted Excel spreadsheet (Microsoft, Redmond, WA).

During clinic appointments, the SPS technician performed a benefits investigation to determine whether a patient's individual insurance plan was contracted with AH SPS. If contracted, the specialty pharmacy team (pharmacist and/or pharmacy technician) offered the service. Patients who used our specialty pharmacy could have their ARV and other maintenance medications dispensed and delivered to their homes (intervention group). For patients with contracted insurance who opted out (control group) of our pharmacy services, they continued to manage their own medication refills through nonintegrated external pharmacies. Individuals without insurance used the Ryan White HIV Medication Assistance Program through the state-contracted pharmacy (Walgreens) or manufacturer assistance through the indigent pharmacy at the Myers Park Clinic. For patients with noncontracted insurance plans or no insurance, the SPS team was still available to help (but could not provide our full service, e.g., medication delivery, synchronization, and refill calls) and could offer financial assistance in the form of grants or copay cards, prior authorization completion, and medication or adherence counseling. Patients without insurance or noncontracted insurance plans were not included in the scope of this study.

Once the patient agreed to enroll, prior authorizations were completed and financial assistance for medication copays were obtained, if necessary, by the SPS technician. The HIV specialty pharmacist then completed a comprehensive medication review (CMR). In addition, during the CMR, the pharmacist evaluated the antiretroviral dose and regimen appropriateness by reviewing kidney and liver function, past therapeutic successes and failures, resistance profiles, comorbidities, and interactions with other medications. If any clinical issues were identified, the pharmacist consulted directly with the prescribing physician face-to-face while in clinic or via EMR messaging. If necessary, the pharmacist ordered and evaluated labs pertinent to ARV treatment.

After the CMR was complete, the pharmacist offered education that included initial counseling on ARV medication administration, importance of strict adherence, drug interactions, and common side effects. During this time, all non-ARV maintenance medications were synced to the ARV medications to ensure that the patients' prescriptions were due at the same time each month. Once all of this was complete, medications were delivered directly to patients' homes (or to the clinic).

The patient was contacted by our specialty pharmacy each month for refill reminders and to assess adherence, medication changes, and regimen tolerability. If the patient missed doses, had side effects, or had medication changes during a monthly refill call, the HIV specialty pharmacist was notified and followed up with the patient. An annual clinical assessment was also completed by the HIV specialty pharmacist. A specialty

\section{FIGURE 1 Atrium Health Specialty Pharmacy} Service Practice Model

Patient enrolls in Atrium Health Specialty Pharmacy Service

Medication reconciliation is completed by specialty pharmacist

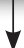

Financial assistance and/or prior authorizations, if any

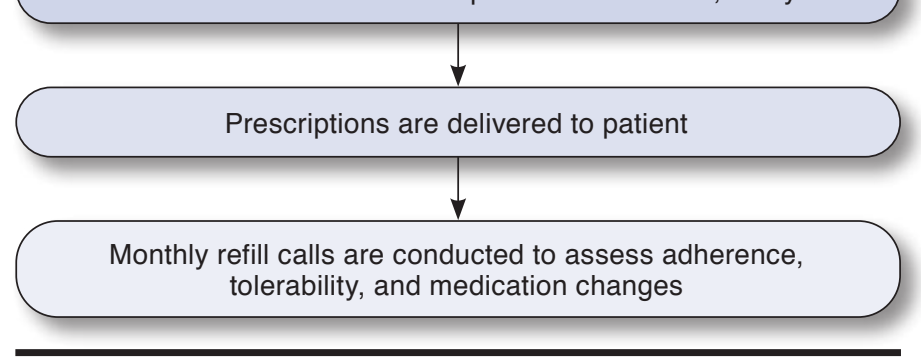

pharmacy patient management software program was used to facilitate scheduling of all refill calls, annual clinical assessments, and documentation of patient encounters and interventions in a standardized format (Figure 1).

\section{Data Collection}

Data were collected from August 7, 2017, to June 30, 2018, through chart review and phone calls. Baseline patient characteristics were collected to include age, gender, race, insurance type, regimen type/complexity, education, mental health conditions, and substance abuse disorders. Prescription refill history was reviewed through pharmacy claim data from the date of entry or declination to the program up to the end of the follow-up. Adherence rate was calculated using MPR. For collection of external pharmacy refill data, manual phone calls were made to each pharmacy to inquire about refill histories. For purposes of this evaluation, refill history included the date that the prescription was filled. Baseline viral load and CD4 count at time of entry or declination to the program was recorded, as well as at the end of the observation period. Three main clinical endpoints included (1) ARV adherence rate, (2) number of patients with a suppressed viral load of $<20$ copies/ $\mathrm{mL}$, and (3) number of patients with CD4 counts of 200 or greater.

\section{Statistical Analysis}

Summary statistics for continuous (mean \pm standard deviation) and categorical variables (count and percentage) were used to describe the study populations and outcomes. MPR was defined as the total number of days that antiretroviral drugs were dispensed by the pharmacy to each patient, divided 
The Effect of an Integrated Health System Specialty Pharmacy on HIV Antiretroviral Therapy Adherence, Viral Suppression, and CD4 Count in an Outpatient Infectious Disease Clinic

TABLE 1

Baseline Patient Characteristics

\begin{tabular}{|c|c|c|c|}
\hline & $\begin{array}{c}\text { Opt-In Group } \\
(n=46)\end{array}$ & $\begin{array}{l}\text { Opt-Out Group } \\
\quad(\mathbf{n}=50)\end{array}$ & $P$ Value \\
\hline Age, mean \pm SD & $53.7 \pm 12.9$ & $58.5 \pm 9.4$ & $0.04^{\mathrm{a}}$ \\
\hline Sex & & & $0.30^{\mathrm{b}}$ \\
\hline Female & $22(47.8)$ & $18 \quad(36.0)$ & \\
\hline Male & $24 \quad(52.2)$ & $32(64.0)$ & \\
\hline Race & & & $0.03^{b}$ \\
\hline White & $6 \quad(13.0)$ & $2 \quad(4.0)$ & \\
\hline Black & $37 \quad(80.4)$ & $48 \quad(96.0)$ & \\
\hline Other & $3 \quad(6.5)$ & $0 \quad(0.0)$ & \\
\hline Insurance status & & & $<0.05^{b}$ \\
\hline Commercial & $9 \quad(19.6)$ & $6 \quad(12.0)$ & \\
\hline Medicaid only & $8 \quad(17.4)$ & $16 \quad(32.0)$ & \\
\hline Medicare only & $4 \quad(8.7)$ & $11 \quad(22.0)$ & \\
\hline Medicare + Medicaid & $25(54.3)$ & $17 \quad(34.0)$ & \\
\hline Education & & & $0.28^{\mathrm{c}}$ \\
\hline Incomplete high school & $16 \quad(34.8)$ & $22(44.0)$ & \\
\hline High school or general education development & $12(26.1)$ & $16 \quad(32.0)$ & \\
\hline Some college or higher & $18 \quad(39.1)$ & $12(24.0)$ & \\
\hline Employed & & & $0.65^{\mathrm{c}}$ \\
\hline No & $36 \quad(78.3)$ & $41 \quad(82.0)$ & \\
\hline Yes & $10 \quad(21.7)$ & $9 \quad(18.0)$ & \\
\hline Homelessness & & & $0.23^{b}$ \\
\hline No & $44 \quad(95.7)$ & $50(100.0)$ & \\
\hline Yes & $2 \quad(4.3)$ & $0 \quad(0.0)$ & \\
\hline Substance abuse or addictive disorders & & & $0.63^{c}$ \\
\hline No & $33 \quad(71.7)$ & $38 \quad(76.0)$ & \\
\hline Yes & $13(28.3)$ & $12(24.0)$ & \\
\hline Psychiatric diagnosis & & & $0.94^{c}$ \\
\hline No & $30 \quad(65.2)$ & $33(66.0)$ & \\
\hline Yes & $16 \quad(34.8)$ & $17 \quad(34.0)$ & \\
\hline Type of regimen & & & $0.48^{\mathrm{b}}$ \\
\hline Integrase strand transfer inhibitor & $33 \quad(71.7)$ & $32(64.0)$ & \\
\hline Protease inhibitor & $4 \quad(8.7)$ & $6 \quad(12.0)$ & \\
\hline Non-nucleoside reverse transcriptase inhibitor & $4 \quad(8.7)$ & $2 \quad(4.0)$ & \\
\hline Other & $5 \quad(10.9)$ & $10(20.0)$ & \\
\hline Daily dosing & & & $0.28^{\mathrm{c}}$ \\
\hline Once & $42 \quad(91.3)$ & $42 \quad(84.0)$ & \\
\hline Twice & $4 \quad(8.7)$ & $8 \quad(16.0)$ & \\
\hline Number of pills in regimen & & & $0.71^{\mathrm{c}}$ \\
\hline 1 & $25(54.3)$ & $23 \quad(46.0)$ & \\
\hline 2 & $9 \quad(19.6)$ & $11 \quad(22.0)$ & \\
\hline$\geq 3$ & $12(26.1)$ & $16 \quad(32.0)$ & \\
\hline
\end{tabular}

Note: all results are $n(\%)$ unless indicated otherwise.

${ }^{a} T$-test.

${ }^{b}$ Fisher's exact test.

cPearson's chi-square test.

$S D=$ standard deviation.

by the patient's total follow-up time in days (calculated as the difference between last and first prescription date plus the supplied days of last prescription) since ARV initiation. ${ }^{16}$ If MPR was greater than $100 \%$, it was truncated to $100 \%$. Either the parametric 2-sample t-test or the nonparametric Wilcoxon rank sum test for continuous variables was performed to evaluate between-group differences. Fisher's exact test was used to compare group percentages. McNemar's test was performed to compare binary data at baseline and the end of follow-up within groups. To better evaluate robustness of the results, sensitivity 
analyses were conducted by including censored patients with less than 6 months of follow-up. A $P$ value of $<0.05$ was considered statistically significant. All analyses were conducted using SAS Enterprise Guide version 7.1 (SAS Institute, Cary, NC).

\section{Results}

A total of 59 patients opted to use AH SPS. Complete data were unable to be collected for 13 patients because of failure to reach the end of observation period. Thus, 46 patients using AH SPS completed the full observation period up to June 30, 2018. Between August 7, 2017, and December 31, 2017, 164 patients with contracted insurance plans were offered the service but opted out of using AH SPS. The main reasons for declination to enroll with AH SPS were loyalty to current pharmacy, use of pill packing services (AH SPS currently does not offer), and fear of medication delivery. Of these 164 patients, 58 were selected from the encrypted Excel spreadsheet using a random generator to serve as the control (opt-out) group. Complete data were unable to be collected on 8 patients because of failure to reach the end of the observation period. Thus, 50 patients using nonintegrated external pharmacies completed the full observation period.

Within both groups, the main reasons for failure to complete the observation period included violation of clinic followup policy (greater than 6 months since last clinic visit), loss of insurance, relocation, and incarceration. For purposes of this study, we did not include patients who failed to complete the observation period in the main analysis but did conduct sensitivity analyses by including those censored patients.

Baseline characteristics of all patients are shown in Table 1. The opt-out group was older $(58.5 \pm 9.4$ vs. $53.7 \pm 12.9, P=0.04)$, and there was a similar ratio of males to females. The majority of patients were black, making up $80.4 \%$ of opt-in patients compared with $96.0 \%$ within the opt-out group $(P=0.03)$. There were nearly twice as many insured through Medicaid in the opt-out group (32.0\%) versus the opt-in group (17.4\%). The majority (80\%-90\%) of patients in each group had either Medicare or Medicaid as their payer source. Although some distributional variations were present in factors such as education, employment status, homelessness, substance disorders, mental comorbidity, type of regimen, daily dosing, and number of pills in regimen, these factors were not statistically significant.

\section{Adherence Rate}

For those patients using AH SPS, the median MPR was higher at 100\% (quartile [Q]; Q1-Q3: 99\%-100\%) versus only 94\% (Q1-Q3: 82\%-99\%) for those patients who opted out of the service (Table 2). This difference was considered to be statistically significant with $P<0.01$. Furthermore, the total number of patients within the opt-in group with an MPR of $90 \%$ or greater was significantly higher when compared with the opt-out group $(89.1 \%$ vs. $64.0 \%, P<0.01)$. The opt-in group

\section{TABLE 2 Medication Possession Ratio by Opt-Out} and Opt-In Groups

\begin{tabular}{|c|c|c|c|}
\hline & $\begin{array}{l}\text { Opt-In Group } \\
(n=46)\end{array}$ & $\begin{array}{l}\text { Opt-Out Group } \\
\qquad(n=50)\end{array}$ & $P$ Value \\
\hline$\geq 90 \%$ & $41 \quad(89.1)$ & $32 \quad(64.0)$ & \\
\hline$<90 \%$ & (10.9) & $(36.0)$ & $<0.01^{a}$ \\
\hline$\geq 95 \%$ & $40 \quad(87.0)$ & $24 \quad(48.0)$ & \\
\hline$<95 \%$ & $(13.0)$ & $26 \quad(52.0)$ & $<0.01^{\mathrm{a}}$ \\
\hline Median (Q1-Q3) & $1.00(0.99-1.00)$ & $0.94(0.82-0.99)$ & $<0.01^{b}$ \\
\hline
\end{tabular}

Note: All results are $n$ (\%) unless indicated otherwise.

aFisher's exact test.

bWilcoxon-Mann Whitney test.

$Q=$ quartile.

also had more patients with a higher MPR of $95 \%$ or greater ( $87 \%$ vs. $48 \%, P<0.01$ ).

\section{Viral Load and CD4 Count}

For the opt-in group, an average of 238 days ( 8 months) lapsed between baseline labs and follow-up labs by the end of the observation period. For the opt-out group, slightly more time passed, with an average of 263 days (8.8 months) between baseline labs and follow-up labs by the end of the observation period. This difference in follow-up did not have any meaningful effect on the results.

Within the opt-in group, 10 of the 46 patients had a detectable viral load of 20 copies $/ \mathrm{mL}$ or greater at baseline. By the end of the observation period, all but 3 reached viral suppression of $<20$ copies $/ \mathrm{mL}$ (21.7\% at baseline vs. $6.5 \%$ at follow-up, $P=0.03$; Table 3 and Figure 2). Of the 3 patients who did not reach viral suppression of $<20$ copies $/ \mathrm{mL}$ per our lab standards, all had viral loads $<200$ copies $/ \mathrm{mL}$. It is important to note that $<200$ copies $/ \mathrm{mL}$ still meets the U.S. Department of Health and Human Services (HHS) standards of viral suppression, and as a result, none of these patients were considered to have failed treatment. At baseline within the opt-out group, 12 of 50 patients had a detectable viral load of 20 copies $/ \mathrm{mL}$ or greater. Only 3 of these 12 patients reached viral suppression by the end of the observation period. For the 9 remaining patients who did not achieve viral suppression, 4 had viral loads of $200 \mathrm{copies} / \mathrm{mL}$ or greater, which could indicate potential treatment failure and does not meet the HHS definition of viral suppression.

When looking at change in viral suppression from baseline to follow-up, patients using AH SPS had statistical improvement in this lab marker, while those opting out did not. Overall, a larger number of patients reached viral suppression within the opt-in group at $93.5 \%$ versus $82.0 \%$ of those within the opt-out group (Table 3). However, when the 2 groups were directly compared, the difference at reaching this endpoint was not statistically significant $(P=0.12)$. 
The Effect of an Integrated Health System Specialty Pharmacy on HIV Antiretroviral Therapy Adherence, Viral Suppression, and CD4 Count in an Outpatient Infectious Disease Clinic

TABLE 3 Clinical Outcomes by Opt-Out and Opt-In Groups

\begin{tabular}{|c|c|c|c|c|c|c|}
\hline & \multicolumn{3}{|c|}{$\begin{array}{l}\text { Opt-In Group } \\
\quad(n=46)\end{array}$} & \multicolumn{3}{|c|}{$\begin{array}{l}\text { Opt-Out Group } \\
\quad(\mathrm{n}=50)\end{array}$} \\
\hline & Baseline & Follow-Up & \multirow[t]{2}{*}{$P$ Value ${ }^{a}$} & Baseline & Follow-Up & \multirow[t]{2}{*}{$P$ Value $^{\mathrm{a}}$} \\
\hline \multicolumn{5}{|l|}{ Viral load, n (\%) } & & \\
\hline Less than 20 & $(78.3)$ & $(93.5)$ & & $(76.0)$ & $(82.0)$ & \\
\hline 20 or greater & $(21.7)$ & (6.5) & 0.03 & $(24.0)$ & (18.0) & 0.41 \\
\hline \multicolumn{7}{|l|}{ CD4, n (\%) } \\
\hline Less than 200 & $(13.0)$ & $(2.2)$ & & $(6.0)$ & $(8.0)$ & \\
\hline 200 or greater & $(87.0)$ & $(97.8)$ & 0.03 & $(94.0)$ & $(92.0)$ & 0.56 \\
\hline
\end{tabular}

Of the 6 patients in the opt-in group who had CD4 counts $<200$ at baseline, all but 1 had improved immune function with a CD 4 count of 200 or greater by the end of the observation period $(P=0.03$; Table 3$)$. There was no improvement in immune function of the 3 patients with CD4 counts $<200$ at baseline within the opt-out group. By the end of the observation period, the number of patients with weakened immune function, as demonstrated by CD $4<200$, increased from 3 to 4 patients.

In the opt-in group, $97.8 \%$ of patients had improved immune function with a CD4 count of 200 or greater versus $92 \%$ of the opt-out patients at follow-up. While there was statistically significant improvement in immune function within the opt-in group from baseline to follow-up, when the 2 groups were compared, the difference in reaching the endpoint of CD4 of 200 or greater did not meet statistical significance $(P=0.36)$.

\section{Sensitivity Analysis}

We further evaluated the results by adding the data of 13 optin and 8 opt-out censored patients with less than 6 months of follow-up into the analysis. The results from the sensitivity analysis showed a similar trend as that in the main analysis. The median MPR in the opt-in group was higher at 100\% (Q1Q3: 98\%-100\%) compared with 94\% ( Q1-Q3: 81\%-99\%) in the group that opted out of the service $(P<0.01$; Appendix A, available in online article).

The opt-in group achieved a higher percentage of MPR as $95 \%$ or greater compared with the opt-out group $(80.7 \%$ vs. $46.2 \%, P<0.01)$. Within the opt-in group, the number of patients who had a detectable viral load of 20 copies $/ \mathrm{mL}$ or greater decreased from 19 (32.2\%) at baseline to 7 (11.9\%) at the end of study $(P=0.02$; Appendix $B$, available in online article). Nine (15.3\%) opt-in patients had CD4 counts that were less than 200 at baseline, whereas all but 2 (3.4\%) had CD4 counts of 200 or greater by the end of the observation period $(P=0.03$; Appendix B). Neither viral load nor CD4 improvement was observed in the opt-out group. When the 2 groups were directly compared, the difference was not statistically significant ( $P=0.48$ and 0.42 for viral load and CD4, respectively).
Multivariable logistic regression models showed similar results after adjusting for age, race, and insurance types.

\section{Discussion}

In this single-center, retrospective cohort evaluation, the opt-in patients demonstrated higher adherence rates in comparison with those managing their own refills through external, nonintegrated pharmacies. Furthermore, our integrated health system specialty pharmacy was able to improve viral load suppression and immune markers from the time of program enrollment to follow-up in patients using our services. AH SPS provided high-touch support to enrolled patients by proactively offering medication refills, identifying and managing drug interactions, assisting with side effect management, and addressing any barriers to adherence. Although viral suppression and immune function were improved in the opt-in group over the opt-out group, the difference was not found to be statistically significant. This could be attributed to small sample size. Ultimately, based on the results of this study, our service has expanded and AH SPS is now managing over 400 HIVinfected patients across all 3 AH outpatient ID clinics.

The MPR calculation was chosen as a marker for adherence because it provides a way to review pharmacy data claims, objectively determine patient adherence rates, and in turn eliminate bias in the form of patient-reported self-adherence. ${ }^{16}$ Using this method, the proportion of patients with an adherence rate of $90 \%$ or greater was significantly higher among patients using AH SPS compared with those managing their own refills through external non-health system pharmacies. The median MPR for enrolled patients was 100\% (IQR: 99\%$100 \%$ ), while only $94 \%$ (IQR: $82 \%-99 \%$ ) for those opting out of the service. As demonstrated in current literature, this has clinical relevance, since high adherence rates are correlated with viral load reduction, transmission reduction, and improved CD4 counts. ${ }^{3-9,13,17,18}$

This association with high adherence was further substantiated by our study because improvements in viral suppression, as well as CD4 counts, from baseline to follow-up were observed for patients using AH SPS. Nearly 94\% of enrolled 
FIGURE 2 Viral Load Suppression and CD4 by Opt-Out and Opt-In Groups

$P=0.12$

Opt-In vs. Opt-Out Viral Load Follow-Up

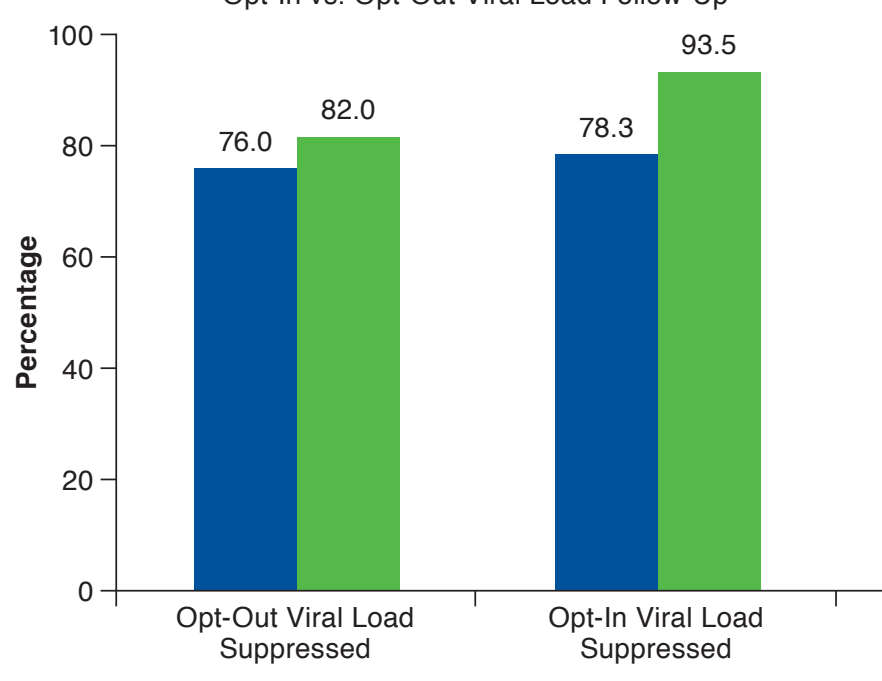

$P=0.36$

Opt-In vs. CD4 Follow-Up

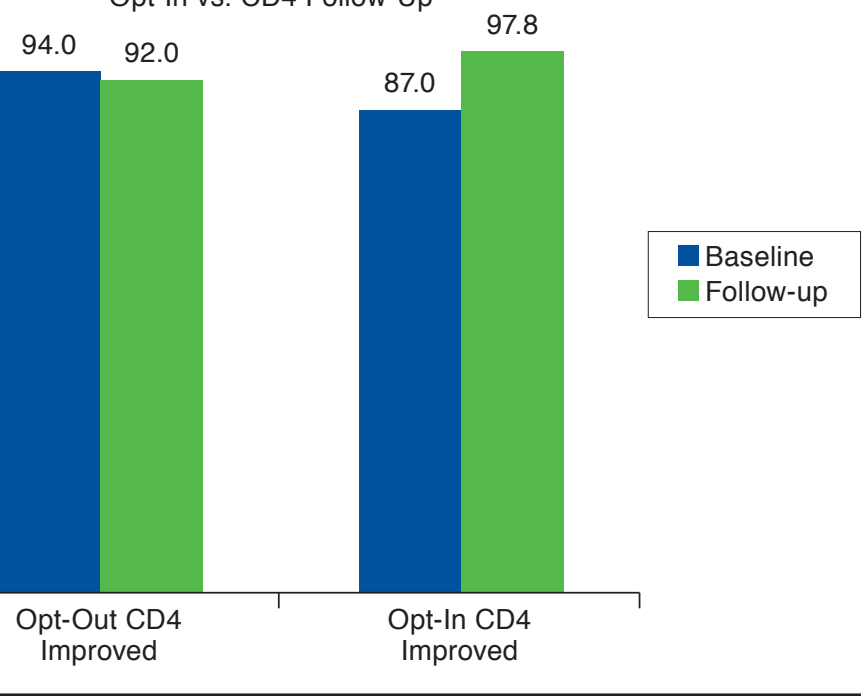

patients had a suppressed viral load of $<20$ copies $/ \mathrm{mL}$, and $98 \%$ had CD4 counts of 200 or greater with no treatment failure or HIV drug resistance by observation end. For those patients within the opt-out group, there was an overall lower adherence rate and no statistically significant improvement in viral load suppression or in immune function from baseline to follow-up.

While improvement in viral suppression and immune function from baseline to follow-up was observed for AH SPS patients, when compared with the opt-out group, there was no statistically significant difference between the 2 at reaching these clinical endpoints. This is important to note, since the within-group before/after changes are short-term indicators of the benefit of pharmacy involvement and do not conclusively prove a difference exists between the 2 groups in terms of improved virologic or immunologic markers. Future studies are needed to assess the full effect of integrated specialty pharmacies.

\section{Limitations}

This evaluation is certainly not without limitation. While a retrospective chart review of specialty pharmacy involvement at a single clinic provided valuable insight, a controlled prospective study would be ideal to better assess the effect of AH SPS. A longer evaluation with a larger sample size would provide more robust results, as well as longer-term clinical outcomes such as increased clinic retention, improved quality of life, decreased drug resistance, and reduction of drug-drug interactions with $\mathrm{AH}$ SPS interventions. In addition, our study was not randomized, which can introduce potential selection bias between 2 groups.
In regard to adherence calculations, MPR may be over- or understated, since dispensing of a medication does not always entail its use. Also, the fill dates collected from the external pharmacies are subject to the accuracy of the individual at the pharmacy location providing the information.

For baseline characteristics, we did not compare the 2 groups for complexity of other medications or comorbidities (outside of psychiatric diagnoses/substance abuse disorders). Patients with multiple comorbidities may be less adherent, given the layer of complexity this adds to the number of medications that they may be required to take on a daily basis. In addition, there were significantly more elderly patients within the opt-out group, although the reasons for this are not entirely clear.

While this study did compare the opt-in (intervention) group to a control group that did not have AH SPS intervention, it should be noted that 27 of the opt-out patients were using external nonintegrated specialty pharmacies instead of regular retail/community (walk-up) pharmacies. While these external specialty pharmacies were not integrated within the health system as with our model, this disparity could skew results in favor of more positive outcomes for the opt-out group, given the higher standard of care, training, and service required of specialty pharmacies versus retail pharmacies. On the other hand, results could be skewed in favor of more positive outcomes for the opt-in patients, since these individuals agreed to enroll in our service, potentially indicating that they may have been more highly engaged in their own health care, more likely to have been adherent, and anticipated a higher degree of follow-up. 
Finally, while the endpoints of suppressed viral load and improved immune function reached statistical significance within the opt-in group from baseline to follow-up, the difference in proportion of patients reaching these endpoints was not significant when compared with the opt-out group. The lack of statistical significance in the group-to-group comparison may be attributed to the small sample sizes or residual confounding.

\section{Conclusions}

$\overline{\mathrm{AH}}$ used a practice model that fully integrated a specialty pharmacy service within an outpatient ID clinic. The goal of this study was to improve clinical outcomes for enrolled patients. Ultimately, this approach to patient care clearly demonstrated higher adherence rates to ARV medication for those enrolled within the program compared with those opting out. Statistically significant improvements in virologic and immunologic markers were also observed for enrolled patients from baseline to follow-up.

While adherence rates were significantly better in the internal specialty pharmacy group, in order to identify a true difference between internal and external pharmacy services in regards to viral load suppression and CD4 count, larger sample sizes may be needed. Further studies with more robust sample sizes are warranted to fully quantify and describe the effect an integrated health system specialty pharmacy can have on HIV clinical outcomes.

\section{Authors}

ELIZABETH BARNES, PharmD, BCACP, AAHIVP, and ADAM GIUMENTA, CPhT, Division of Pharmacy, Atrium Health, Charlotte, North Carolina. JING ZHAO, MD, PhD, Center for Outcomes Research and Evaluation, and MARC JOHNSON, MD, Department of Medicine, Division of Infectious Disease, Atrium Health, Charlotte, North Carolina.

AUTHOR CORRESPONDENCE: Elizabeth Barnes, PharmD, BCACP, AAHIVP, Clinical Coordinator, Atrium Health, 4400 Golf Acres Dr., Bldg. J, Ste B-1, Charlotte, NC 28208. Tel.: 704.512.6057;

E-mail: Elizabeth.Barnes@atriumhealth.org.

\section{DISCLOSURES}

No outside funding supported this study. The authors have nothing to disclose.

\section{REFERENCES}

1. Centers for Disease Control and Prevention. Diagnoses of HIV infection in the United States and dependent areas, 2017. HIV Surveillance Report. Vol. 29. November 2018. Available at: https://www.cdc.gov/hiv/pdf/library/ reports/surveillance/cdc-hiv-surveillance-report-2017-vol-29.pdf. Accessed January 15, 2020
2. Centers for Disease Control and Prevention. HIV in the southern United States. CDC Issue Brief. September 2019. Available at: https://www.cdc.gov/hiv/ pdf/policies/cdc-hiv-in-the-south-issue-brief.pdf. Accessed January 22, 2020.

3. U.S. Department of Health and Human Services, Panel on Antiretroviral Guidelines for Adults and Adolescents. Guidelines for the use of antiretroviral agents in HIV-1 infected adults and adolescents. Updated December 18, 2019. Available at: https://aidsinfo.nih.gov/guidelines/html/l/adult-andadolescent-arv/0. Accessed January 15, 2020.

4. Friedland FH, Williams A. Attaining higher goals in HIV treatment: the central importance of adherence. AIDS. 1999;13 (Suppl 1):S61-72.

5. Sethi AK, Celentano DD, Gange SJ, Moore RD, Gallant JE. Association between adherence to antiretroviral therapy and human immunodeficiency virus resistance. Clin Infect Dis. 2003;37(8):1112-18.

6. Paterson DL, Swindells S, Mohr J, et al. Adherence to protease inhibitor therapy and outcomes in patients with HIV infection. Ann Intern Med. 2000;133(1):21-30.

7. Bangsberg DR, Hecht FM, Charlebois Ed, et al. Adherence to protease inhibitors, HIV-1 viral load, and development of drug resistance in an indigent population. AIDS. 2000;14(4):357-66.

8. Bangsberg DR, Kroetz DL, Deeks SG. Adherence-resistance relationships to combination HIV antiretroviral therapy. Curr HIV/AIDS Rep. 2007;4(2):65-72.

9. Fairley CK, Permana A, Read TR. Long-term utility of measuring adherence by self-report compared with pharmacy record in a routine clinic setting. HIV Med. 2005;6(5):366-69.

10. Hirsch JD, Rosenquist A, Best BM, Miller TA, Gilmer, TP. Evaluation of the first year of a pilot program in community pharmacy: HIV/AIDS medication therapy management for Medi-Cal beneficiaries. J Manag Care Pharm. 2009;15(1):32-41. Available at: https://www.jmcp.org/doi/10.18553/ jmcp.2009.15.1.32.

11. Cocohoba J, Murphy P, Pietrandoni G, Guglielmo J. Improved antiretroviral refill adherence in HIV-focused community pharmacies. J Am Pharm Assoc (2003). 2012;52(5):e67-e73.

12. Dilworth TJ, Klein PW, Mercier RC, et al. Clinical and economic effects of a pharmacist-administered antriretroviral therapy adherence clinic for patients living with HIV. J Manag Care Spec Pharm. 2018;24(2):165-72. Available at: https://www.jmcp.org/doi/10.18553/jmcp.2018.24.2.165.

13. Horberg MA, Hurley LB, Silverberg MJ, Kinsman CJ, Quesenberry CP. Effect of clinical pharmacists on utilization of and clinical response to antiretroviral therapy. J Acquir Immune Defic Syndr. 2007;44(5):531-39.

14. Colgan K, Beacher R. Importance of specialty pharmacy to your health system. Am J Health Syst Pharm. 2015;72(9):753-56.

15. Gilbert E, Gerzenshtein, L. Integration of outpatient infections disease clinic pharmacy services and specialty pharmacy services for patients with HIV infection. Am J Health Syst Pharm. 2016;73(11):757-63.

16. Crowe M. Evaluating your clinical programs with prescription claim records. Pharmacy Today. July 1, 2013. Available at: https://www.pharmacytoday.org/article/S1042-0991(15)31267-6/pdf. Accessed January 15, 2020.

17. Henderson KC, Hindman J, Johnson SC, et al. Assessing the effectiveness of pharmacy-based adherence interventions on anti-retroviral adherence in persons with HIV. AIDS Patient Care STDS. 2011;25(4):221-28.

18. Castillo E, Palepu A, Beardsell A, et al. Outpatient pharmacy care and HIV viral load response among patients on HAART. AIDS Care. 2004;16(4):446-47. 
The Effect of an Integrated Health System Specialty Pharmacy on HIV Antiretroviral Therapy Adherence, Viral Suppression, and CD4 Count in an Outpatient Infectious Disease Clinic

\begin{tabular}{|c|c|c|c|}
\hline APPENDI & $\begin{array}{l}\text { Medication } \\
\text { Opt-Out an } \\
\text { Counting }\end{array}$ & $\begin{array}{l}\text { Ossession Rat } \\
\text { Opt-In Grou } \\
\text { Censored Pa }\end{array}$ & $\begin{array}{l}\text { by } \\
\text { After } \\
\text { nts }^{a}\end{array}$ \\
\hline & $\begin{array}{l}\text { Opt-In Group } \\
\quad(\mathbf{n}=59)\end{array}$ & $\begin{array}{l}\text { Opt-Out Group } \\
\quad(n=58)\end{array}$ & $P$ Value \\
\hline$\geq 90 \%$ & $50 \quad(87.7)$ & $33 \quad(63.5)$ & \\
\hline$<90 \%$ & $7 \quad(12.3)$ & $19 \quad(36.5)$ & $<0.01^{b}$ \\
\hline$\geq 95 \%$ & $46 \quad(80.7)$ & $24 \quad(46.2)$ & \\
\hline$<95 \%$ & $11 \quad(19.3)$ & $28 \quad(53.8)$ & $<0.01^{b}$ \\
\hline Median (Q1-Q3) & $1.00(0.98-1.00)$ & $0.94(0.81-0.99)$ & $<0.01^{\mathrm{c}}$ \\
\hline $\begin{array}{l}\text { Note: all results are } \\
\text { aData not available } \\
\text { bFisher's exact test. } \\
\text { cWilcoxon-Mann W } \\
Q=\text { quartile. }\end{array}$ & $\begin{array}{l}\text { subjects. Missing } \\
\text { test. }\end{array}$ & $e s: n=8$. & \\
\hline
\end{tabular}

\section{APPENDIX B Clinical Outcomes by Opt-Out and Opt-In Groups After Counting for Censored Patients ${ }^{a}$}

\begin{tabular}{|c|c|c|c|c|c|c|c|}
\hline & \multicolumn{3}{|c|}{$\begin{array}{l}\text { Opt-In Group } \\
\quad(\mathrm{n}=59)\end{array}$} & \multicolumn{3}{|c|}{$\begin{array}{c}\text { Opt-Out Group } \\
(\mathrm{n}=58)\end{array}$} & \multirow{2}{*}{$\begin{array}{l}\text { Group vs. } \\
\text { Group } \\
P \text { Value }\end{array}$} \\
\hline & Baseline & Follow-Up & $P$ Value & Baseline & Follow-Up & P Value & \\
\hline Viral load, n (\%) & & & $0.02^{b}$ & & & $0.41^{b}$ & $0.48^{c}$ \\
\hline Less than 20 & $40 \quad(67.8)$ & $48 \quad(81.3)$ & & $43 \quad(74.1)$ & $42 \quad(72.4)$ & & \\
\hline 20 or greater & $19 \quad(32.2)$ & $7 \quad(11.9)$ & & $15 \quad(25.9)$ & $9 \quad(15.5)$ & & \\
\hline Missing & & $4 \quad(6.8)$ & & & $7 \quad(12.1)$ & & \\
\hline CD4, n (\%) & & & $0.03^{b}$ & & & $0.56^{\mathrm{b}}$ & $0.42^{\mathrm{d}}$ \\
\hline Less than 200 & $9 \quad(15.3)$ & $2 \quad(3.4)$ & & $3 \quad(5.2)$ & $4 \quad(6.9)$ & & \\
\hline 200 or greater & $50 \quad(84.7)$ & $53 \quad(89.8)$ & & $55 \quad(94.8)$ & $47 \quad(81.0)$ & & \\
\hline Missing & & $4 \quad(6.8)$ & & & $7 \quad(12.1)$ & & \\
\hline
\end{tabular}

a Data not available for all subjects. Missing values: viral load $=11, C D 4=11$.

${ }^{b}$ McNemar's test for within groups.

'Pearson's chi-square test.

'Fisher's Exact test. 